$6 \quad *$ corresponding author

7

\section{Abstract}

\title{
Dormancy Breaking Treatments in Northern Wild Rice (Zizania palustris L.) Seed Suggest a
} Physiological Source of Dormancy Lillian McGilp ${ }^{1}$, Aaron Semington ${ }^{1}$, and Jennifer Kimball ${ }^{1 *}$

\author{
${ }^{1}$ Department of Agronomy and Plant Genetics, University of Minnesota, St Paul, Minnesota, 55108
}

Keywords: northern wild rice, Zizania palustris, seed dormancy, germination, physiological dormancy

Dormancy is a limiting factor for breeding in northern wild rice (NWR; Zizania palustris L). This study developed a dormancy curve and tested a combination of scarification and hormone treatments, across three timepoints, for their ability to break dormancy in NWR and produce viable seedlings and plants. A dormancy curve was established across 9 months post-harvest, which showed maximum germination (95 $\%)$ by 17 weeks post-harvest and high germination $(\geq 81 \%)$ through the rest of the testing period. Next, dormancy breaking treatments were tested. At 1 week post-harvest, few seeds germinated $(\leq 15 \%)$ across all treatment combinations. However, sulfuric acid increased germination shortly after harvest (5.8 \%), compared to water $(0.5 \%)$ and $\mathrm{NaClO}(0 \%)$ but resulted in stunted seedlings, all but one of which died shortly thereafter. At 7 weeks, sulfuric acid treated seeds did not result in significantly higher germination than water and maximum germination was still below $15 \%$. By 11 weeks post-harvest, the water treatments had the highest germination and resulted in the most viable plants, indicating that dormancy had begun to break naturally and exceeded the effect of the other scarification treatments. Hormonal treatments had no significant effect on germination or seed viability and no strong conclusions could be drawn about their effect on seedling or plant health. Due to the inability of early germinated seed to consistently produce viable plants and the increase in germination following sufficient cold storage, it is likely that NWR seed has intermediate or deep physiological dormancy. 


\section{Introduction}

30 Northern wild rice (NWR; Zizania palustris L.) is an outcrossing, annual aquatic grass in the Poaceae family.

31 The species grows naturally in lakes and streams across the Great Lakes region of the United States and

32 Canada, and provides food and habitat to many species in aquatic ecosystems (Steeves, 1952; Huseby,

33 1997; Biesboer, 2019). In addition to natural stands, NWR has been cultivated in irrigated paddies since

34 the 1950s, with the largest production in Minnesota and California (Oelke and Porter, 2016). NWRs unique

35 seed physiology is a major challenge for the development of new cultivars, particularly due to the limited

36 longevity of seed in current storage conditions. This loss of viability during NWR storage is related to the

37 intermediately recalcitrant, or desiccation sensitive, seed, which is commonly associated with short-term

38 viability and limits ex-situ seed storage (Probert and Brierley, 1989; Kovach and Bradford, 1992a; Dickie

and Pritchard, 2002; McGilp et al., 2020). NWR seed also has a dormancy period of about three to six months, during which cool $\left(1-3^{\circ} \mathrm{C}\right)$, submerged, and dark conditions are necessary for the stratification of seed (Simpson, 1966; Cardwell et al., 1978; Grombacher et al., 1997). The dormancy period of NWR seed slowing the progress of breeding. Although both recalcitrance and dormancy can be limiting factors in the breeding of NWR, little is known about the mechanisms underlying these traits or the relationship between them. This study aims to increase the knowledge about the basic biology underlying dormancy in NWR.

Seed dormancy is the absence of germination, within a certain period of time, despite the presence of favorable environmental conditions, including but not limited to, temperature, light quality, and the

51 dormancy have been defined in various ways over time, they can be broken down into 5 broad categories

52 including: physical (PY), or dormancy related to impermeability of the seed coat, physiological (PD), where

53 there is a block to the expansion of the embryo, morphological (MD), in which the embryo is

54 undifferentiated or underdeveloped, morphophysiological (MPD), a combination of MD and PD, or 
combinational (PY + PD), a combination of PY and PD (Baskin and Baskin, 2004, 2014a). It is thought that in NWR seed there are multiple mechanisms for the control of dormancy (Oelke, 1982). The tough, waxy seed coat of NWR appears to block the embryo from expanding, either due to impermeability restricting the imbibition of seed or via physical restriction by the seed coat, which is evidenced by the increase in germination upon mechanical removal of the pericarp overlaying the embryo (Woods and Gutek, 1974; Cardwell et al., 1978; Oelke, 1982). Additionally, it is likely that there is hormonal inhibition of embryo growth in NWR as evidenced by large quantities of abscisic acid (ABA) found in dormant NWR

62 seed and reduced germination of hulled seeds when suspended in an aqueous solution of hulls (Cardwell et 63 al., 1978; Albrecht et al., 1979; Oelke and Albrecht, 1980; Grombacher et al., 1997). However, the specific type of dormancy in NWR has not been clearly defined.

In an effort to learn more about dormancy in NWR, as well as increase the number of possible breeding cycles in a year, several studies have evaluated methods of overcoming dormancy. Some research has focused on breaking dormancy by breaching the seed coat, including the physical removal of portions of the pericarp with a scalpel, dissecting needle, or through the use of abrasive granules, as well as the application of chemicals such as ethanol, chloroform, sodium hypochlorite, and acetone (Simpson, 1966;

71 NWR seed, which did not always correspond to higher seedling vigor. Other studies have tested the 72 application of hormones to overcome seed dormancy in NWR. In particular, researchers have evaluated the 73 efficacy of applications of gibberellic acid $\left(\mathrm{GA}_{3}\right)$, 6-benzyl adenine (BA), and kinetin for the germination 74 of dormant seed (Simpson, 1966; Cardwell et al., 1978; Oelke and Albrecht, 1980). As compared to 75 treatments that were only scarified, treatments with $\mathrm{GA}_{3}$, especially when combined with kinetin, had a 76 greater effect on the germination of NWR seed. Similar studies in white rice (Oryza sativa L.) have also 77 demonstrated the efficacy of the application of kinetin and $\mathrm{GA}_{3}$ in overcoming seed dormancy (Cohn and 78 Butera, 1982; Miyoshi and Sato, 1997; Vieira et al., 2002). While some NWR seed treatments have shown 79 modest increases in germination, there is not yet a sufficiently efficacious method on which breeding 80 programs can rely. 
Despite the breeding challenges imposed by it, little is known about the dormancy of NWR seed,

82 particularly compared to other cultivated plant species. Although previous studies have evaluated the

83 efficacy of various treatments for breaking dormancy in NWR, many of them have used dehulled seed or

84 seed with punctured pericarps, processes which are not feasible for large scale breeding and have resulted

85 in weakened seedlings (Oelke and Albrecht, 1978, 1980). Additionally, only a handful of these studies have

86 been conducted early in the dormancy period, during which maximal inhibition would be present. Finally,

87 previous studies have not evaluated the use of sulfuric acid as a means of weakening the pericarp of NWR,

88 despite its use in other species (Li et al., 1999; Purohit et al., 2015; Lata et al., 2018; Xiong et al., 2018).

89 Therefore, a re-evaluation of dormancy breaking techniques for NWR is needed. The objectives of this

90 study were to 1) Evaluate the efficacy of the combination of mechanical and hormonal treatments for early

91 dormancy break in NWR and 2) Assess the effect of early dormancy break on the viability of the resulting

92 NWR plants. In this study, mechanical and hormonal treatments were applied individually or successively

93 to NWR seed, at three timepoints, throughout the initial stages of dormancy. The efficacy of the treatments

94 was evaluated through the measurement of germination, metabolic activity, seedling size, and plant health.

\section{Materials and Methods}

$97 \quad$ Plant Materials

98 In 2019, the NWR cultivated variety 'Itasca-C12' and the breeding line 'K2EF-C16', representing 99 genotypes with average and early germination, respectively, were used to establish a dormancy curve. 100 Itasca-C12 was broadcast planted at a density of $112 \mathrm{~kg} \mathrm{ha}^{-1}$, in a grower's dike irrigated, field in Gully, 101 MN. K2EF-C16 was broadcast planted at a density of $15.7 \mathrm{~kg} \mathrm{ha}^{-1}$ in a $12 \mathrm{x} 15 \mathrm{~m}$, in a dike-lined research 102 paddy at the University of Minnesota North Central Research and Outreach Center (NCROC), in Grand 103 Rapids, $\mathrm{MN}\left(47.2372^{\circ} \mathrm{N}, 93.5302^{\circ} \mathrm{W}\right.$, and $392 \mathrm{~m}$ elevation). The genotypes were both planted on May $10416^{\text {th }}$ of 2019 , open pollinated in their respective paddies, and then hand harvested on September $3^{\text {rd }}$ and $4^{\text {th }}$ 105 of 2019, respectively. 
For the dormancy breaking experiments, the NWR variety 'Barron' was chosen, as it is a productive variety with good germination, and excess seed was readily available for the experiment. Germination was an important consideration for this study, as the recalcitrance of NWR seed limits the viability of seed stocks in storage. Seeds were tractor-planted planted on May $12^{\text {th }}$ of 2020 , at $15.7 \mathrm{~kg} \mathrm{ha}^{-1}$, in a $153 \times 27 \mathrm{~m}$

110 dike irrigated research plot, with $3 \mathrm{~m}$ single rows, spaced $0.38 \mathrm{~m}$ apart, and $1 \mathrm{~m}$ alleys, for a final plant density

111 of 1 plant per $0.09 \mathrm{~m}^{2}$. Plants were open pollinated and seed was hand harvested on September 10th of 2020.

112 Following harvest and processing, seed was stored submerged in $\mathrm{dH}_{2} \mathrm{O}$ in heavy sealed plastic bags, in the 113 dark, at $3^{\circ} \mathrm{C}$ until the beginning of each trial.

\section{Germination and Tetrazolium Testing}

116 To assess seed viability, seeds were placed in petri dishes lined with filter paper and $20 \mathrm{ml}$ of $\mathrm{dH}_{2} 0$. Plates 117 were then randomized within blocks, in a Conviron-E15 growth chamber (Winnipeg, Canada), for 118 germination testing. The growth chamber was set to 15 -hour days at $20^{\circ} \mathrm{C}$ and 9-hour nights at $14^{\circ} \mathrm{C}$. To 119 keep seeds moist through-out the germination testing period, $\mathrm{dH}_{2} \mathrm{O}$ was added to petri dishes as necessary. 120 After 14 days, the number of germinated seeds, as defined by coleoptile emergence equal to the length of 121 the seed, were quantified. The germinated seeds from the dormancy treatment experiment were then placed 122 in $4 \mathrm{oz}$ jars with $20 \mathrm{ml}$ of $\mathrm{dH}_{2} 0$ for 1 week, in preparation for seedling evaluations and remained in the 123 growth chamber under the same conditions as for germination testing. $\mathrm{dH}_{2} 0$ was added to jars as necessary 124 to keep seeds submerged.

Ungerminated seeds were evaluated for metabolic activity to estimate seed viability with a protocol 126 adapted from the tetrazolium testing handbook (Peters, 2000). Briefly, seed was bisected longitudinally to 127 expose the embryo, then suspended in a $0.2 \%$ solution of 2,3,5 triphenyl tetrazolium chloride (Mp 128 Biomedicals Inc, Santa Ana, CA) for 2 hours. Seed was then triple-rinsed and the number of stained 129 embryos was quantified. 
132 To produce a dormancy curve for NWR, seed was evaluated over a 9-month period ( 38 weeks), starting 133 from harvest, on September $5^{\text {th }}, 2019$, through May 27th, 2020. Every two weeks during this period, 3 134 replicates of 20 seeds were pulled from submerged cold storage. Seeds were germination tested, under the 135 same conditions as is described above. Any seed that did not germinate, was subsequently tetrazolium 136 stained, as described above, to assess seed viability. From these data, a dormancy curve was produced and 137 an estimate of the weeks post-harvest at which $50 \%$ of viable seed germinated was calculated, as described 138 in the data analysis section.

\section{Dormancy Breaking Experiment}

141 To develop improved methodology for overcoming dormancy in NWR, we evaluated several treatments, over the first three months of the dormancy period. The experiment was repeated 3 times, with the first experiment starting on September $21^{\text {st }}, 2020,1$ week post-harvest, the second on October $27^{\text {th }}, 7$ weeks post-harvest, and the third on November $24^{\text {th }}, 11$ weeks post-harvest. The trials were split into five steps: primary treatment, targeting the seed coat, secondary treatment, using hormones to stimulate the embryo, germination and tetrazolium testing, seedling evaluations, and plant health ratings. Each trial was set up as

147 a randomized complete block design, with 5 blocks of 20 seeds per primary and secondary treatment combination.

To evaluate the possibility of seed coat imposed dormancy, or that related to the tissues surrounding the embryo, three primary treatments were tested, including a 2 hour soak in $300 \mathrm{ml}$ of $2.63 \%$ sodium hypochlorite ( $\mathrm{NaClO}$ ) (Oelke and Albrecht, 1980), a 45 second wash in $200 \mathrm{ml}$ of $98 \%$ sulfuric acid (SA), and a 45 second wash in $\mathrm{dH}_{2} 0$, as a control. Following the treatment of seeds with $\mathrm{NaClO}$, $\mathrm{SA}$, or water, 153 seeds were rinsed 3 times with $300 \mathrm{ml}$ of $\mathrm{dH}_{2} 0$. To evaluate the potential for embryo imposed dormancy, 154 or that related to the embryo or endosperm, secondary hormone treatments were immediately applied 155 following primary treatments. Secondary treatments included: $0.1 \mathrm{mM}$ gibberellic acid $\left(\mathrm{GA}_{3}\right)($ Research 156 Products International, Mt Prospect, IL), $1 \mathrm{mM}$ kinetin (K) (Chem Impex International Inc, Bensenville, 157 IL), a combination of $0.1 \mathrm{mM} \mathrm{GA}_{3}$ and $1 \mathrm{mM} \mathrm{K}$, and a $\mathrm{dH}_{2} 0$ control. Seeds were placed in sealed, $4 \mathrm{oz}$ 
plastic jars, with $20 \mathrm{ml}$ of secondary treatment solution and stored at room temperature $\left(\sim 24^{\circ} \mathrm{C}\right)$, in the dark, for 24 hours (Oelke and Albrecht, 1980). After 24 hours, each jar of seed was rinsed for 30 seconds under running water.

\section{Evaluation of Seedling and Plant Vigor}

163 To evaluate the seedling and plant vigor of seeds that germinated, seedlings and plants were assessed by 164 several methods. After 1 week of growth in the growth chamber, seedlings were measured from root tip to 165 the top of shoot tissue. Seedlings were then randomized in a greenhouse, set to 12 -hour days at $24^{\circ} \mathrm{C}$ and 166 12-hour nights at $18^{\circ} \mathrm{C}$. Seedlings were grown in fully submerged, $25 \mathrm{~cm}$ deep, $3.2 \mathrm{~cm}$ radius cone-tainers, amended with $22.4 \mathrm{~kg} \mathrm{ha}^{-1}$ of urea (Alpha Chemicals, Stoughton, MA) and $48.8 \mathrm{~kg} \mathrm{ha}^{-1}$ of Sprint 330 iron chelate (BASF, Ludwigshafen, Germany) for 30 days. After 30 days, the root and shoot tissue of each plant were measured separately, using a measuring tape, and plants were given a health rating of 1-4 (1: a dead plant, 2: a plant with significantly stunted growth and thin leaves, 3: a plant with relatively normal growth

171 but with minor stunting of stem or leaf tissue, 4: A healthy plant with no stunting) (Figure 1).

\section{Data Analysis}

174 Analyses were done in Rstudio, version 1.2.5001 (Rstudio-team, 2019). Data was first run through standard

175 residual diagnostic plots, including residuals versus fitted, normal Q-Q, scale-location and residuals versus 176 leverage, to assess data quality. An analysis of variance (ANOVA) was conducted for germination and 177 tetrazolium testing results. Significant results from the ANOVA were evaluated using the post hoc Tukey 178 LSD test from the 'agricolae' package, using a Bonferroni adjustment for p-values (Mendiburu, 2019). Due 179 to uneven sample sizes in the seedling and plant rating data, statistical analyses could not be done on these 180 data. The 'ggplot2' package (Wikham, 2016) was used to produce all graphs in this publication. 
seeds that were actually viable. A modified $\mathrm{LD}_{50}$ calculation, using germination in place of toxicology data, from the Rstudio package 'MASS' (Venables and Ripley, 2002), was then used to calculate the time during the dormancy period at which $50 \%$ of all viable seed had germinated $\left(\mathrm{D}_{50}\right)$ per genotype, using the above calculation of true dormancy break.

\section{Results}

\section{Evaluation of NWR Dormancy}

The pattern of dormancy break over the expected 3-6 month dormancy period for NWR has not been reported previously. In this study, the percentage of germination was recorded and plotted across a 9-month period, following harvest, in order to establish a dormancy curve. The germination of Itasca-C12 and K2EFC16 was tracked from September 2019 through May of 2020. Both seed lines tested had reached $95 \%$ germination by January $2^{\text {nd }}$, approximately 4 months (17 weeks) post-harvest (Figure 2 ). This falls within the frequently recorded 3-6 month dormancy window for NWR. From January ( 17 weeks) through the end of the study, in May ( $\sim 35$ weeks), the germination remained high, with means between $81-98 \%$. Both lines followed a similar pattern of germination through January, though K2EF-C16 continuously had higher germination through that period. The germination gap between lines began to lessen around November $(\sim 10$ weeks), at which time it appears that Itasca-C12 caught up and remained comparable with K2EF-C16 for the remainder of the study. The calculated $\mathrm{D}_{50}$ value, or the timepoint at which $50 \%$ of viable seed had broken dormancy, was shorter for K2EF-C16, at only 5.3 weeks, compared with that of Itasca-C12, at 6.2 weeks (Figure 2). However, both had reached their $\mathrm{D}_{50}$ prior to 3 months, or the expected start of dormancy break for NWR.

\section{Dormancy Breaking Experiment - Germination and Viability}

In an effort to increase the number of breeding cycles possible in a year, treatments were tested for their ability to break dormancy early in NWR. The efficacy of the combination of primary and secondary dormancy breaking treatments was assessed using results from germination tests, tetrazolium staining, and 

than $15 \%$ (Figure 3a). Germination at this point was similar to that seen in the dormancy curve (Figure 2).

211 Although germination was low, there was a significant effect of primary treatments on the germination of

212 seed (Table 1). Seeds treated with sulfuric acid had significantly higher germination than other primary

213 treatments, $5.8 \%$ compared with $0.53 \%$ and $0 \%$ for water and $\mathrm{NaClO}$, respectively, when averaged across

214 secondary treatments (Table 3a). There was no significant effect on germination due to secondary 215 treatments at this point (Table 1).

217 a little lower than the equivalent time period, Oct. $30^{\text {th }}$ ( $\sim 8$ weeks), in the dormancy curve (Figure 2 ). Despite

218 the low germination, there was a significant effect of primary treatments on the germination of seed (Table

219 1). Sulfuric acid treated seeds had the highest average germination at $7.3 \%$, but the germination was not 220 significantly different than that of water primary treated seed, at $4.5 \%$ (Table $3 \mathrm{~b}$ ). The proximity of the 221 germination values may be due to the interaction between water as a primary treatment and the

$222 \mathrm{GA}_{3}$ secondary treatment, which had comparable germination to those of the sulfuric acid treatments, 223 increasing the average germination of the water primary treatment (Figure 3b). Both sulfuric acid and water 224 had higher average germination than $\mathrm{NaClO}$, at only $1.3 \%$ (Table 3b). Despite the germination peak 225 between water and $\mathrm{GA}_{3}$, no significant differences in germination were attributable to secondary treatments 226 or to the combination of primary and secondary treatments (Table 1).

At 11 weeks post-harvest, the maximum germination increased to about $30 \%$, which is quite a bit 228 lower than that seen in the dormancy curve (60\% for Itasca-C12 and $73 \%$ for $\mathrm{K} 2 \mathrm{EF}-\mathrm{C} 16)$ at the equivalent 229 time period, Nov. $25^{\text {th }}(\sim 11.5$ weeks) (Figure 3c; Figure 2$)$. Primary treatments had a significant effect on 230 germination (Table 1). However, the water primary treated seed now showed significantly higher 231 germination than either sulfuric acid or $\mathrm{NaClO}$ treatments, $22.3 \%$ compared to $12.5 \%$ and $12.0 \%$, 232 respectively, when averaged across secondary treatments (Table 3c). Secondary treatments still showed no 233 significant effect on germination. 
The viability of all non-germinating seed was tracked during the trials, to determine whether the lack of germination was due to dormant or dead seed. At 1 week post-harvest, there were no differences in viability between primary or secondary treatments, or the combination of the two (Table 2). For all

237 treatments, about $80 \%$ of the embryos stained, indicating high viability (Figure 3d). By 7 weeks post-

238 harvest, the percent of stained seed had decreased slightly, with a range of 73-83\% (Figure 3e). Once again, 239 no significant differences were found between treatments (Table 2). At 11 weeks post-harvest, there was a 240 significant effect of primary treatment on the staining of seed (Table 2). While the range of staining for

$241 \mathrm{NaClO}$ and water primary treated seeds remained stable, compared to the previous trial, seeds treated with 242 sulfuric acid had significantly lower staining, with a range of just $26-45 \%$ (Figure $3 f$ ). There was no effect 243 of secondary treatments on the tetrazolium staining of seed.

246 For the purpose of breeding, it is not enough to break dormancy early, the resulting plants must also remain

247 viable thereafter. Therefore, seedling and plant health was assessed for all seed that germinated during the trials. At 1 week post-harvest, only 23 seeds germinated, resulting in a small data set for this time point. treatment and a secondary treatment with $\mathrm{GA}_{3}$ and Kinetin (Figure 4a). However, there was only one seed to measure for this treatment, making this data difficult to interpret. Many of the seeds that germinated at this time, were those treated with a sulfuric acid primary treatment. Of the germinated seeds treated with sulfuric acid, the secondary treatment with the lowest mean seedling length, $16.91 \mathrm{~cm}$, was kinetin, while the highest, at $26.08 \mathrm{~cm}$, was $\mathrm{GA}_{3}$ and kinetin (Table $\mathrm{S} 1$ ). The only plant during this trial that had a length above 0 , by the time plant ratings were collected, was that treated with sulfuric acid, followed by $\mathrm{GA}_{3}$. It 256 had a plant length of $451.11 \mathrm{~cm}$ and a plant health rating of 3 (Figure $4 \mathrm{~d} ; 5 \mathrm{~g}$ ). All remaining plants had died 257 and had a length of $0 \mathrm{~cm}$ and a health rating of 1.

At 7 weeks post-harvest, 52 seeds germinated, with representation from all primary treatments 259 (Figure 3a). The seedlings with the highest mean length, $94.61 \mathrm{~cm}(\mathrm{n}=8)$, were treated with $\mathrm{SA}$ and $\mathrm{GA}_{3}$ 
261 some seedlings treated with water and $\mathrm{GA}_{3}$ did have lengths matching the highest overall mean length,

262 others were much shorter, resulting in a lower mean for this treatment combination (Figure 4b;

263 Supplementary Table 1). Overall, seeds treated with $\mathrm{NaClO}$ resulted in short seedlings $(\leq 40 \mathrm{~cm})$, relative

264 to other primary treatments. Seedling length did not appear to predict plant length, as seedlings with the

265 highest mean seedling length, SA with $\mathrm{GA}_{3}$, resulted in one of the shortest mean plant lengths

266 (Supplementary Table 1). The highest mean plant length, $631.80 \mathrm{~cm}$, resulted from seeds treated with SA,

267 then water, closely followed by those treated with water, then water, at $563.23 \mathrm{~cm}$ (Supplementary Table

268 1). However, $\sim 63 \%$ of seedlings from this trial resulted in short plants $(\leq 200)$ and $75 \%$ had plant health

269 ratings of 1 or 2 (Figure $4 \mathrm{e} ; 5 \mathrm{~h})$.

By 11 weeks post-harvest 182 seeds had germinated, a marked increase from either of the two

271 previous trials. As these seeds were distributed across all primary and secondary treatments, it appeared

272 that seed may have been naturally beginning the process of seed dormancy break. However, as with the

273 previous trial, the seedlings with the highest mean length, $93.96 \mathrm{~cm}$, were treated with SA, then $\mathrm{GA}_{3}$,

274 although the lowest were treated with $\mathrm{NaClO}$, then water (Supplementary Table 1). In the previous trial,

275 seeds treated with $\mathrm{NaClO}$ had a higher rate of plant death, relative to other primary treatments, but by the

27611 week post-harvest trial, seeds treated with $\mathrm{NaClO}$ actually had a higher mean plant length than either

277 other primary treatment, when averaged across all secondary treatments (Supplementary Table 1).

278 Interestingly, the longest mean seedling lengths, still resulted in one of the shortest mean plant lengths

279 (Supplementary Table 1). However, in general seedling length was not a good predictor of plant length.

280 During this trial $\sim 44 \%$ of seedlings resulted in short plants and $\sim 69 \%$ of plants had a plant health rating

281 of 1 or 2 (Figure 4f; 5i).

283 Discussion

284 Evaluation of NWR Dormancy 
An understanding of when dormancy break begins, peaks, and ends will help researchers to form a more complete picture of the process of dormancy break in NWR. The dormancy curve developed in this study showed that from January ( $\sim 17$ weeks post-harvest) through the end of the study, in May ( $\sim 35$ weeks postharvest), the germination remained high, indicating that no significant loss in viability had taken place. However, because this study only covered about 9 months post-harvest, it was likely too short to demonstrate the drop in viability that is commonly recorded for NWR (Kovach and Bradford, 1992a; Berjak and Pammenter, 2008; McGilp et al., 2020). Additionally, the $\mathrm{D}_{50}$ for K2EF-C16 was shorter than that of Itasca-C12. This is consistent with previous anecdotal observations within the breeding program, in which K2EF-C16 has broken dormancy early, relative to Itasca-C12, which falls closer to the average dormancy break of breeding germplasm. However, it is interesting that the $\mathrm{D}_{50}$ occurred at less than 2 months following harvest, given the expected 3-6 month dormancy period for NWR (Simpson, 1966; Cardwell et intrapopulation variation in the dormancy and germination of seed is also found in many other species, including Linum perenne L, Spergula arvensis, Sinapis arvensis, and Viminaria juncea (Meyer and Kitchen, 1994; Andersson and Milberg, 1998; Jones and Nielson, 1999; Baskin and Baskin, 2004; Lacerda et al., 2004; Liyanage and Ooi, 2015). Given the heterogeneous and heterozygous nature of open-pollinated breeding populations, these types of variation are likely to exist in NWR.

\section{Dormancy Breaking Experiment - Germination and Viability}

304 Seed dormancy and germination are traits controlled by both genetics and a variety of environmental factors 305 (Koornneef et al., 2002; Skubacz, 2017). Many genes are involved in the initiation, maintenance, and 306 decline of seed dormancy, which are regulated by the presence or absence of hormones and certain 307 environmental cues including but not limited to: high or low temperatures, oxygen or nitrate availability, 308 and the time for embryo growth and expansion (Baskin and Baskin, 2004; Finch-Savage and Leubner309 Metzger, 2006; Finkelstein et al., 2008; Duermeyer et al., 2018). Although there are various types of dormancy, at a basic level, the regulation of dormancy involves the interplay of the growth potential of the 
311 embryo and its physical or chemical restraint by the surrounding seed tissues (Kucera et al., 2007; Baskin 312 and Baskin, 2014a). presence of seed dormancy. Previous studies have evaluated these traits in order to improve the understanding of NWR seed physiology and thereby increase breeding efficiency (Cardwell et al., 1978; Oelke and Albrecht, 1978; Albrecht et al., 1979; Kovach and Bradford, 1992a; b; McGilp et al., 2020). However, due to the relatively recent cultivation of NWR compared to other crops, and the unique combination of recalcitrance and dormancy, the mechanisms underlying dormancy in NWR are not well understood. This study sought to identify effective and efficient methods of early dormancy break in NWR for the purpose of breeding, the results of which could also hint at the types of dormancy regulation present 321 in the seed. and continuing through 11 weeks post-harvest, to determine the efficacy of primary and secondary treatments for early dormancy break in NWR. Across all timepoints germination was low, never reaching above $30 \%$, regardless of treatment, although tetrazolium tests indicated that this was not a matter of seed viability. Such low germination would not provide adequate plants for breeding purposes. However, some differences were seen between primary treatments, though none were identified between secondary treatments at any time point.

At 1 week post-harvest, the sulfuric acid treated seed had significantly higher germination than $\mathrm{NaClO}$ or water, when averaged across secondary treatments. Sulfuric acid is effective in breaking seed 331 dormancy in a number of species with physical dormancy including field bindweed (Convolvulus arvensis 332 L.), Medicago spp., and Trifolium spp., among others (Balouchi and Sanavy, 2006; Kimura and A, 2012; 333 Baskin and Baskin, 2014b; Xiong et al., 2018). No NaClO treated seed germinated at this timepoint, perhaps 334 indicating that $\mathrm{NaClO}$ was not sufficient to break through or weaken the seed coats at their thickest point 335 during the dormancy period to allow imbibition to take place. While previous results have indicated that 336 treatment of freshly harvested NWR seed with $\mathrm{NaClO}$ was effective for germination, these studies have 
used dehulled and scarified seed, effectively providing a double scarification treatment (Oelke and Albrecht, 1980). Additionally, while $\mathrm{NaClO}$ is effective for dormancy break in some species, in others it can have a negative effect on germination, and in some it can have no effect whatsoever, even within the same plant families (Rosbakh et al., 2019). By 7 weeks post-harvest sulfuric acid treated seed did not have significantly higher germination than the primary water treated seed but both still had higher germination than $\mathrm{NaClO}$ treated seed. At 11 weeks post-harvest the water treated seed had significantly higher germination than either of the other primary treatments. This may indicate that by this time point the embryo covering layers

344 were undergoing natural weakening processes, perhaps triggered by sufficient cold stratification, allowing 345 for further growth of the embryo, as occurs in seeds with physiological dormancy (Bewley et al., 2013; Baskin and Baskin, 2014a). As this was close to 3 months post-harvest, it falls approximately within the 347 expected timeframe for dormancy break in NWR (Simpson, 1966; Cardwell et al., 1978; Oelke and 348 Albrecht, 1980). secondary treatments. Seeds treated with $\mathrm{NaClO}$ had similar levels of viability to water treated seed, though

354 lower on average. Water and $\mathrm{NaClO}$ treated seed retained levels of viability near that of the previous 355 timepoints, whereas SA treated seeds had significantly lower viability. This likely indicates that SA had a 356 deleterious effect on the viability of seed by the 11 week timepoint, most likely due to the SA reaching and 357 damaging the embryo. Additionally, seed treated with $\mathrm{NaClO}$ had lower germination than that treated with 358 water but the seed showed no real loss in viability, perhaps indicating that $\mathrm{NaClO}$ was not truly an effective 359 treatment, so much as a neutral one. Previous research has also shown only a modest effect of $\mathrm{NaClO}$ on 360 the germination of NWR seed, even when combined with mechanical scarification (Oelke and Albrecht, 361 1980). 
While seeds were viable and able to germinate this early in the dormancy period, they did not result in viable seedlings. Previous NWR seed research has also found that while dormancy can be broken shortly after harvest by the removal of structures covering the embryo, the resulting seedlings are weak (Oelke and Albrecht, 1980). Little research has been devoted to excising embryos of NWR to assess the growth of seedlings. One study found that when embryos of NWR seed were excised, they could germinate normally,

367 perhaps indicating that the physiological dormancy is at a non-deep level (LaRue and Avery, 1983).

368 However, it is unknown at what point in development these seeds were harvested or whether the germinated 369 seeds would have resulted in viable plants. Additionally, the results have not been replicated. The inability of an excised embryo to produce normal seedlings is one of the factors used to differentiate between intermediate and deep physiological dormancy, though it is often difficult to distinguish between the levels of physiological dormancy (Baskin and Baskin, 2004, 2014a). physiological dormancy, requiring sufficient cold stratification in order to germinate and produce viable seedlings (Baskin and Baskin, 2014a). Previous studies have concluded that NWR must have physical dormancy, due to the appearance of an impermeable seed coat and the observation that removal of certain

377 portions of the seed coat can induce germination (Simpson, 1966; Cardwell et al., 1978; Oelke and Albrecht, 378 1978). However, the actual imbibition of NWR seed has not been directly measured (Dalziell et al., 2019), nor has the structure of the NWR pericarp, in order to determine with confidence that it is truly impermeable. Additionally, a review of nearly 900 tree and shrub species found that while about $14 \%$ of desiccation sensitive seeds displayed physiological dormancy, only $1.4 \%$ of the species had physical dormancy,

382 resulting from an impermeable seed coat (Tweddle et al., 2003; Jaganathan, 2021). While that study found 383 that most desiccation sensitive seed displayed morphological or morphophysiological dormancy, we 384 believe that the embryo of dormant NWR seed is both differentiated and developed, based upon the pattern 385 of embryo staining when tetrazolium is applied shortly after harvest. However, a more complete study of 386 embryo development is needed to confirm these anecdotal observations. Therefore, while previous studies 387 have stated otherwise, it is possible that the constraint of the embryo covering layers is not due to 
impermeability but rather to the mechanical constraint imposed by the seed coat or the low growth potential of the embryo at harvest, which is alleviated over time in cold stratification. Previous research has also demonstrated the need for cold stratification for dormancy break in NWR (Kovach and Bradford, 1992a; McGilp et al., 2020). In Najas marina and Trapella sinensis, two annual, aquatic plants with seed dormancy, cold stratification was also required for the termination of dormancy, leading the authors to suggest that their seed may by physiologically dormant (Handley and Davy, 2005; Kato and Kadono, 2011). While there are species whose seeds have combinational dormancy, or both physiological and physical dormancy, it is rare and unlikely to occur when deep dormancy is present. In addition, combinational dormancy within desiccation sensitive seed was entirely absent in a dataset of 900 tree and brush species (Tweddle et al., 2003; Baskin and Baskin, 2004). Regardless of the cause of the restriction to dormancy imposed by the seed coat, researchers have noted that damage to the pericarp is helpful but not sufficient for successful dormancy break and subsequent survival of seedlings in NWR (Simpson, 1966; Grombacher et al., 1997). In this experiment, secondary hormone treatments showed no significant effect on the germination in NWR. A lack of dormancy break in response to $\mathrm{GA}_{3}$ can indicate that seed has deep or intermediate PD, as has been found in some Forbes species as well as Rosa multibracteata (Baskin and Baskin, 2004; Hoyle et al., 2008; Zhou et al., 2009). It is also possible that different hormones are involved in the dormancy process of NWR, as ethylene, brassinosteroids, and nitrate are also known to be involved in the cessation of dormancy in other species, or that the hormones used in this study were applied at ineffective rates

407 (Kucera et al., 2007; Baskin and Baskin, 2014a; Toorop, 2015). While there were some significant 408 interactions between primary and secondary treatments in relation to seedling and plant health, they were 409 not consistent across time, making it difficult to draw any broad conclusions about their efficacy. Previous 410 studies have found mixed results on the efficacy of the application of $\mathrm{GA}_{3}$, with or without disruption of the 411 seed coat, for the induction of dormancy break in NWR (Simpson, 1966; Oelke and Albrecht, 1980).

412 However, ABA has been found in high concentrations in the hulls, pericarps, and embryos of dormant 413 NWR seed and the application of hulls and pericarps from freshly harvested seed to non-dormant seed has 
414 resulted in the inhibition of germination (Cardwell et al., 1978; Albrecht et al., 1979). This indicates that

415 ABA is involved in the induction of dormancy in NWR but the connection between $\mathrm{GA}_{3}$ and other tested

416 hormones for the efficacious reduction of dormancy of large NWR seed lots is less clear. As the effect of

$417 \mathrm{GA}_{3}$ application on dormancy break is one of the differentiating factors between non-deep and deep PD

418 (Baskin and Baskin, 2004), the inconclusiveness of these tests further complicates the ability to characterize

419 dormancy in NWR. Ultimately, sufficient time under cold stratification conditions has been shown to be

420 the most effective strategy for the production of sufficient healthy NWR plants for the purpose of breeding

421 (Grombacher et al., 1997).

Therefore, early forced germination of the types tested here and previously for NWR are unlikely

423 to result in a sufficient number of healthy NWR plants for the purpose of breeding. Transcriptomic analysis

424 over the course of NWR dormancy, as has been conducted in Chenopodium quinoa and Panax

425 quinquefolius (Qi et al., 2015; Wu et al., 2020), is one tool that should be explored in the future, to better

understand the dormancy process in NWR and to develop more efficacious strategies for increasing the

427 speed of breeding. Additionally, characterization of the imbibition of dormant and non-dormant seed and

428 the physical structure of the embryo and surrounding tissues will further illuminate the presence or absence

429 of physical dormancy. Such strategies will elucidate active pathways and physical barriers throughout the course of dormancy, ultimately informing future breeding strategies.

\section{Conclusion}

433 A dormancy curve for NWR has been developed across 9 months following harvest. This study gave insight

434 into the type of dormancy present in NWR. While previous research has concluded that NWR has physical

435 dormancy, evidence from this and previous studies point to a physiological source of dormancy. Due to the

436 focus on treatments aimed at physical dormancy, there has been little headway made in the production of

437 healthy plants through early dormancy break, for breeding of NWR. Future studies assessing the imbibition,

438 physical structure, and expression levels of dormant and non-dormant NWR seed will allow for improved

439 methodology development, leading to more efficient breeding strategies. 


\section{References}

Albrecht, K. A., Oelke, E. A. and Brenner, M. L. (1979) Abscisic acid levels in the grain of wild rice. Crop Science 19, 671-676. doi:10.2135/cropsci1979.0011183X001900050032x.

Andersson, L. and Milberg, P. (1998) Variation in seed dormancy among mother plants, populations and years of seed collection. Seed Science Research 8, 29-38. doi:DOI: 10.1017/S0960258500003883.

Balouchi, H. R. and Sanavy, S. A. M. M. (2006) Effect of gibberellic acid, prechilling, sulfuric acid and potassium nitrate on seed germination and dormancy of annual medics. Pakistan Journal of Biological Sciences 9, 2875-2880. doi:10.3923/pjbs.2006.2875.2880.

Baskin, J. M. and Baskin, C. C. (2004) A classification system for seed dormancy. Seed Science Research 14, 1-16. doi:DOI: 10.1079/SSR2003150.

Baskin, C. C. and Baskin, J. M. (2014a) Chapter 3 - Types of seeds and kinds of seed dormancy, pp. 3777 in Baskin, C. C. and Baskin, J. M. (Eds.) Seeds: Ecology, biogeography, and evolution of dormancy and germination. San Diego, Academic Press doi:https://doi.org/10.1016/B978-0-12-4166776.00003-2.

Baskin, C. C. and Baskin, J. M. (2014b) Chapter 6 - Germination ecology of seeds with physical dormancy, pp. 145-185 in Baskin, C. C. and Baskin, J. M. (Eds.) Seeds: Ecology, biogeography, and evolution of dormancy and germination. San Diego, Academic Press doi:https://doi.org/10.1016/B978-0-12-416677-6.00006-8.

Berjak, P. and Pammenter, N. W. (2008) From Avicennia to Zizania: Seed recalcitrance in perspective. Annals of Botany 101, 213-228. doi:10.1093/aob/mcm168.

Bewley, J. D., Bradford, K. J., Hilhorst, H. W. M. and Nonogaki, H. (2013) Dormancy and the control of germination, pp. 247-297 in Bewley, J. D., Bradford, K. J., Hilhorst, H. W. M., and Nonogaki, H. (Eds.) Seeds: Physiology of Development, Germination and Dormancy. New York, NY, Springer New York doi:10.1007/978-1-4614-4693-4_6.

Biesboer, D. D. (2019) The ecology and conservation of wild rice, Zizania palustris 1., in North America. Acta Limnologica Brasiliensia 31, e102.

Cardwell, V. B., Oelke, E. A. and Elliott, W. A. (1978) Seed dormancy mechanisms in wild rice (Zizania aquatica). Agronomy 70, 481-484.

Cohn, M. A. and Butera, D. L. (1982) Seed dormancy in red rice (Oryza sativa). II. Response to cytokinins. Weed Science 30, 200-205.

Dalziell, E. L., Baskin, C. C., Baskin, J. M., Young, R. E., Dixon, K. W. and Merritt, D. J. (2019) Morphophysiological dormancy in the basal angiosperm order Nymphaeales. Annals of botany 123, 95-106. doi:10.1093/aob/mcy142.

Dickie, J. B. and Pritchard, H. W. (2002) Systematic and evolutionary aspects of desiccation tolerance in seeds, pp. 239-260 in Black, M. and Pritchard, H. W. (Eds.) Dessication and Survival in Plants: Drying Without Dying. CABI.

Duermeyer, L., Khodapanahi, E., Yan, D., Krapp, A., Rothstein, S. J. and Nambara, E. (2018) Regulation of seed dormancy and germination by nitrate. Seed Science Research 28, 150-157. doi:https://doi.org/10.1017/ S096025851800020X. 
Finch-Savage, W. E. and Leubner-Metzger, G. (2006) Seed dormancy and the control of germination. The New Phytologist 171, 501-523.

Finkelstein, R., Reeves, W., Ariizumi, T. and Steber, C. (2008) Molecular aspects of seed dormancy. Annual Review of Plant Biology 59, 387-415. doi:10.1146/annurev.arplant.59.032607.092740.

Grombacher, A. W., Porter, R. A. and Everett, L. A. (1997) Breeding wild rice. Plant Breeding Reviews 14 237-265. doi:10.1002/9780470650073.ch8.

Handley, R. J. and Davy, A. J. (2005) Temperature effects on seed maturity and dormancy cycles in an aquatic annual, Najas marina, at the edge of its range. Journal of Ecology 93, 1185-1193.

Hilhorst, H. W. M. (1995) A critical update on seed dormancy. I. Primary dormancy. Seed Science Research 5, 61-73. doi:DOI: 10.1017/S0960258500002634.

Hoyle, G. L., Steadman, K. J., Daws, M. I. and Adkins, S. W. (2008) Physiological dormancy in forbs native to south-west Queensland: Diagnosis and classification. South African Journal of Botany 74, 208-213. doi:https://doi.org/10.1016/j.sajb.2007.11.005.

Huseby, J. T. (1997) Use of cultivated wild rice paddies and associated habitats by migrating and breeding waterfowl in northwest Minnesota. http://login.ezproxy.lib.umn.edu/login?url=https://www.proquest.com/dissertations-theses/usecultivated-wild-rice-paddies-associated/docview/304378734/se-2?accountid=14586.

Jaganathan, G. K. (2021) Ecological insights into the coexistence of dormancy and desiccation-sensitivity in Arecaceae species. Annals of Forest Science 78, 10. doi:10.1007/s13595-021-01032-9.

Jones, T. A. and Nielson, D. C. (1999) Intrapopulation genetic variation for seed dormancy in indian ricegrass. Journal of Range Management 52, 646-650. doi:10.2307/4003636.

Kato, R. and Kadono, Y. (2011) Seed germination traits of Trapella sinensis (Trapellaceae), an endangered aquatic plant in Japan: Conservation implications. Aquatic Botany 95, 258-261. doi:https://doi.org/10.1016/j.aquabot.2011.08.002.

Kimura, E. and A, I. M. (2012) Seed scarification methods and their use in forage legumes. Research Journal of Seed Science 5, 38-50. doi:10.3923/rjss.2012.38.50.

Koornneef, M., Bentsink, L. and Hilhorst, H. (2002) Seed dormancy and germination. Current Opinion in Plant Biology 5, 33-36. doi:https://doi.org/10.1016/S1369-5266(01)00219-9.

Kovach, D. A. and Bradford, K. J. (1992a) Temperature dependence of viability and dormancy of Zizania palustris var. interior seeds stored at high moisture contents. Annals of Botany 69, 297-301.

Kovach, D. A. and Bradford, K. J. (1992b) Imbibitional damage and desiccation tolerance of wild rice (Zizania palustris) seeds. Journal of Experimental Botany 43, 747-757. doi:10.1093/jxb/43.6.747.

Kucera, B., Cohn, M. A. and Leubner-Metzger, G. (2007) Plant hormone interactions during seed dormancy release and germination. Seed science research 15, 281-307. doi:10.1079/SSR2005218.

Lacerda, D. R., Lemos Filho, J. P., Goulart, M. F., Ribeiro, R. A. and Lovato, M. B. (2004) Seeddormancy variation in natural populations of two tropical leguminous tree species: Senna multijuga (Caesalpinoideae) and Plathymenia reticulata (Mimosoideae). Seed Science Research 14, 127-135. doi:DOI: 10.1079/SSR2004162.

LaRue, C. D. and Avery, G. S. (1983) The development of the embryo of Zizania aquatica in the seed and in artificial culture. Bulletin of the Torrey Botanical Club 65, 11-21. 
Lata, S., Sharma, G., Garg, S. and Joshi, M. (2018) Effect of different chemical treatments on germination of strawberry seeds. International Journal of Current Microbiology and Apllied Sciences 7, 1270-1724. doi:https://doi.org/10.20546/ijcmas.2018.703.150.

Li, X., Baskin, J. M. and Baskin, C. C. (1999) Anatomy of two mechanisms of breaking physical dormancy by experimental treatments in seeds of two North American Rhus species (Anacardiaceae). American Journal of Botany 86, 1505-1511. doi:https://doi.org/10.2307/2656788.

Liyanage, G. S. and Ooi, M. K. J. (2015) Intra-population level variation in thresholds for physical dormancy-breaking temperature. Annals of botany 116, 123-131. doi:10.1093/aob/mcv069.

McGilp, L., Duquette, J., Braaten, D., Kimball, J. and Porter, R. (2020) Investigation of variable storage conditions for cultivated northern wild rice and their effects on seed viability and dormancy. Seed Science Research. doi:10.1017/S0960258520000033.

Mendiburu, F. de (2019) Agricolae: Statistical procedures for agricultural research.

Meyer, S. E. and Kitchen, S. G. (1994) Life history variation in blue flax (Linum perenne: Linaceae): Seed germination phenology. American Journal of Botany 81, 528-535. doi:10.2307/2445726.

Miyoshi, K. and Sato, T. (1997) The effects of kinetin and gibberellin on the germination of dehusked seeds of indica and japonica rice (Oryza sativa L.) under anaerobic and aerobic conditions. Annals of Botany 80, 479-483. doi:https://doi.org/10.1006/anbo.1997.0470.

Oelke, E. A. (1982) Wild rice production in Minnesota. St. Paul, Minn., University of Minnesota, Agricultural Extension Service.

Oelke, E. A. and Albrecht, K. A. (1978) Mechanical scarification of dormant wild rice seed. Agronomy Journal 70, 691-694.

Oelke, E. A. and Albrecht, K. A. (1980) Influence of chemical seed treatments on germination of dormant wild rice seeds. Crop Science 20, 595-598.

Oelke, E. A. and Porter, R. A. (2016) Wildrice, Zizania: Overview, pp. 130-139 in Corke, H., Faubion, J., W, W. C., and Seetharaman, K. (Eds.) Encyclopedia of Food Grains. Kidlington, Oxford, UK, Academic Press.

Peters, J. ed. (2000) Tetrazolium testing handbook, in Contributions to the Handbook on seed testing ; no. 29. Lincoln, NE, Association of Official Seed Analysts: Tetrazolium testing committee.

Probert, R. J. and Brierley, E. R. (1989) Desiccation intolerance in seeds of Zizania palustris is not related to developmental age or the duration of post-harvest storage. Annals of Botany 64, 669-674.

Purohit, S., Nandi, S. K., Palni, L. M. S., Giri, L. and Bhatt, A. (2015) Effect of sulfuric acid treatment on breaking of seed dormancy and subsequent seedling establishment in Zanthoxylum armatum dc: an endangered medicinal plant of the himalayan region. National Academy Science Letters 38, 301304. doi:10.1007/s40009-015-0349-5.

Qi, J., Sun, P., Liao, D., Sun, T., Zhu, J. and Li, X. (2015) Transcriptomic analysis of American ginseng seeds during the dormancy release process by RNA-Seq. PLoS ONE 10, 1-17. doi:10.1371/journal.pone.0118558.

Rosbakh, S., Hülsmann, L., Weinberger, I., Bleicher, M. and Poschlod, P. (2019) Bleaching and cold stratification can break dormancy and improve seed germination in Cyperaceae. Aquatic Botany 158, 103128. doi:https://doi.org/10.1016/j.aquabot.2019.103128.

Rstudio-team (2019) Rstudio: Integrated development for R. 
Simpson, G. M. (1966) A study of germination in the seed of wild rice (Zizania aquatica). Canadian Journal of Botany 44, 1-9.

Skubacz, A. (2017) Seed dormancy: The complex process regulated by abscisic acid, gibberellins, and other phytohormones that makes seed germination work, in Mohamed El-Esawi (Ed.) Phytohormones Signaling Mechanisms and Crosstalk in Plant Development and Stress Responses. IntechOpen doi:10.5772/intechopen.68735.

Steeves, T. A. (1952) Wild rice: Indian food and a modern delicacy. Economic Botany 6, 107-142.

Toorop, P. E. (2015) Nitrate controls testa rupture and water content during release of physiological dormancy in seeds of Sisymbrium officinale (L.) Scop. Seed Science Research 25, 138-146. doi:DOI: 10.1017/S0960258514000397.

Tweddle, J. C., Dickie, J. B., Baskin, C. C. and Baskin, J. M. (2003) Ecological aspects of seed desiccation sensitivity. Journal of Ecology 91, 294-304.

Venables, W. N. and Ripley, B. D. (2002) Modern applied statistics with S. Fourth. New York, Springer.

Vieira, A. R., Vieira, M. das G. G. C., Fraga, A. C., Oliveira, J. A. and Santos, C. D. dos (2002) Action of gibberellic acid (GA3) on dormancy and activity of alpha-amylase in rice seeds. Revista brasileira de sementes 24, 43-48. doi:10.1590/S0101-31222002000100008.

Wikham, H. (2016) ggplot2- Elegant graphics for data analysis. New York, Springer-Verlag.

Woods, D. L. and Gutek, L. H. (1974) Germinating wild rice. Canadian Journal of Plant Science 54, 423-424. doi:10.4141/cjps74-064.

Wu, Q., Bai, X., Wu, X., Xiang, D., Wan, Y., Luo, Y., Shi, X., Li, Q., Zhao, J., Qin, P., Yang, X. and Zhao, G. (2020) Transcriptome profiling identifies transcription factors and key homologs involved in seed dormancy and germination regulation of Chenopodium quinoa. Plant Physiology and Biochemistry 151, 443-456. doi:10.1016/j.plaphy.2020.03.050.

Xiong, R., Wang, Y., Wu, H., Ma, Y., Jiang, W. and Ma, X. (2018) Seed treatments alleviate dormancy of field bindweed (Convolvulus arvensis L.). Weed Technology 32, 564-569. doi:10.1017/wet.2018.46.

Zhou, Z.-Q., Bao, W.-K. and Wu, N. (2009) Dormancy and germination in Rosa multibracteata Hemsl. \& E. H. Wilson. Scientia Horticulturae 119, 434-441. doi:https://doi.org/10.1016/j.scienta.2008.08.017. 
Table 1. Analysis of variance (ANOVA) of percent germination $(\% \mathrm{G})$ of treated northern wild rice (NWR; Zizania palustris L.) seed at 1, 7, and 11 weeks post-harvest following primary (2 hour soak in $300 \mathrm{ml}$ of $2.63 \%$ sodium hypochlorite, a 45 second wash in $200 \mathrm{ml}$ of $98 \%$ sulfuric acid, or a 45 second wash in $\left.\mathrm{dH}_{2} \mathrm{O}\right)$ and secondary $\left(0.1 \mathrm{mM}\right.$ gibberellic acid $\left(\mathrm{GA}_{3}\right), 1 \mathrm{mM}$ kinetin $(\mathrm{K}), \mathrm{GA}_{3}$ and $\mathrm{K}$, or $\left.\mathrm{dH}_{2} 0\right)$ treatments.

\begin{tabular}{|l|r|r|r|r|r|r|}
\hline 1 week post-harvest & & & & & & \\
\hline Rep & Df & Sum sq & Mean sq & F-value & $\operatorname{Pr}(>\mathrm{F})$ & 0.710 \\
\hline Primary Treatment & 4 & 28.50 & 7.12 & 0.54 & $<0.001$ \\
\hline Secondary Treatment & 3 & 412.77 & 206.38 & 15.52 & 0.776 \\
\hline Primary x Secondary & 6 & 34.68 & 5.78 & 0.43 & 0.852 \\
\hline Residuals & 44 & 584.93 & 13.29 & & & \\
\hline 7 weeks post-harvest & & & & & & 0.153 \\
\hline & Df & Sum sq & Mean sq & F-value & $\operatorname{Pr}(>\mathrm{F})$ & $<0.01$ \\
\hline Rep & 4 & 187.74 & 46.93 & 1.76 & \\
\hline Primary Treatment & 2 & 361.73 & 180.87 & 6.80 & 0.382 \\
\hline Secondary Treatment & 3 & 83.40 & 27.80 & 1.04 & 0.279 \\
\hline Primary x Secondary & 6 & 206.80 & 34.47 & 1.30 & \\
\hline Residuals & 44 & 1170.92 & 26.61 & & & \\
\hline 11 weeks post-harvest & & & & & & 0.37 \\
\hline & Df & Sum sq & Mean sq & F-value & $\operatorname{Pr}(>\mathrm{F})$ & 0.732 \\
\hline Rep & 4 & 651.94 & 162.99 & 1.76 & 0.882 \\
\hline Primary Treatment & 2 & 1349.54 & 674.77 & 7.30 & \\
\hline Secondary Treatment & 3 & 119.36 & 39.79 & 0.43 & \\
\hline Primary x Secondary & 6 & 215.98 & 36.00 & 0.39 & \\
\hline Residuals & 44 & 4067.93 & 92.45 & & & \\
\hline
\end{tabular}


Table 2. Analysis of variance (ANOVA) of percent tetrazolium-stained seed of treated northern wild rice (NWR; Zizania palustris L.) seed at 1, 7, and 11 weeks post-harvest, following primary (2 hour soak in $300 \mathrm{ml}$ of $2.63 \%$ sodium hypochlorite, a 45 second wash in $200 \mathrm{ml}$ of $98 \%$ sulfuric acid, or a 45 second wash in $\left.\mathrm{dH}_{2} \mathrm{O}\right)$ and $\left(0.1 \mathrm{mM}\right.$ gibberellic acid $\left(\mathrm{GA}_{3}\right), 1 \mathrm{mM}$ kinetin $(\mathrm{K}), \mathrm{GA}_{3}$ and $\mathrm{K}$, or $\left.\mathrm{dH}_{2} 0\right)$ secondary

602 treatments.

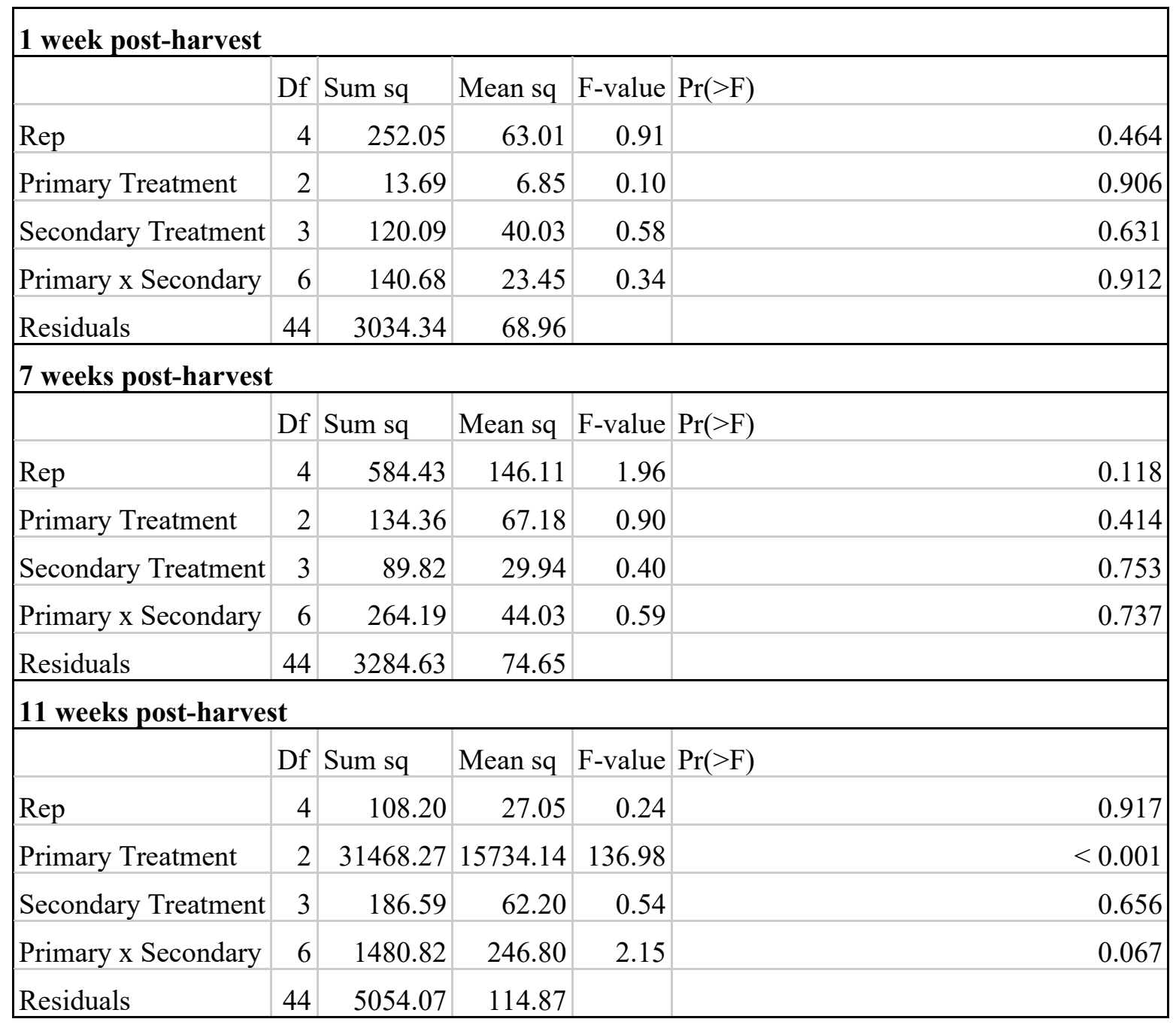

603 
Table 3. Tukey's LSD, with a Bonferroni adjustment to p-values, for all significant effects of dormancy breaking treatments on the percent of germination $(\% \mathrm{G})$ or tetrazolium $(\mathrm{Tz})$ staining of seed from northern

607 wild rice (NWR; Zizania palustris L.), at 1, 7, and 11 weeks post-harvest.

\begin{tabular}{|l|r|l|}
\hline \multicolumn{2}{|l|}{ A. 1 week post-harvest } & \\
\hline Primary Treatments & Average Germination (\%) & Groups \\
\hline Water & 0.53 & $\mathrm{~b}$ \\
\hline Sulfuric Acid & 5.81 & $\mathrm{a}$ \\
\hline $\mathrm{NaClO}$ & 0.00 & $\mathrm{~b}$ \\
\hline
\end{tabular}

\section{B. 7 weeks post-harvest}

\begin{tabular}{|l|r|l|}
\hline Primary Treatments & Average Germination (\%) & Groups \\
\hline Water & $4.50 \mathrm{ab}$ \\
\hline Sulfuric Acid & $7.31 \mathrm{ab}$ \\
\hline $\mathrm{NaClO}$ & $1.30 \mathrm{~b}$ \\
\hline
\end{tabular}

\section{11 weeks post-harvest}

Primary Treatments Average Germination (\%) $\quad$ Groups

\begin{tabular}{|l|r|l|}
\hline Water & 22.3 & $\mathrm{a}$ \\
\hline Sulfuric Acid & 12.50 & $\mathrm{~b}$ \\
\hline $\mathrm{NaClO}$ & 12.00 & $\mathrm{~b}$ \\
\hline Primary Treatments & Average Tz Staining (\%) & Groups \\
\hline Water & 82.48 & $\mathrm{a}$ \\
\hline Sulfuric Acid & 32.17 & $\mathrm{~b}$ \\
\hline $\mathrm{NaClO}$ & 78.81 & $\mathrm{a}$ \\
\hline
\end{tabular}

608 

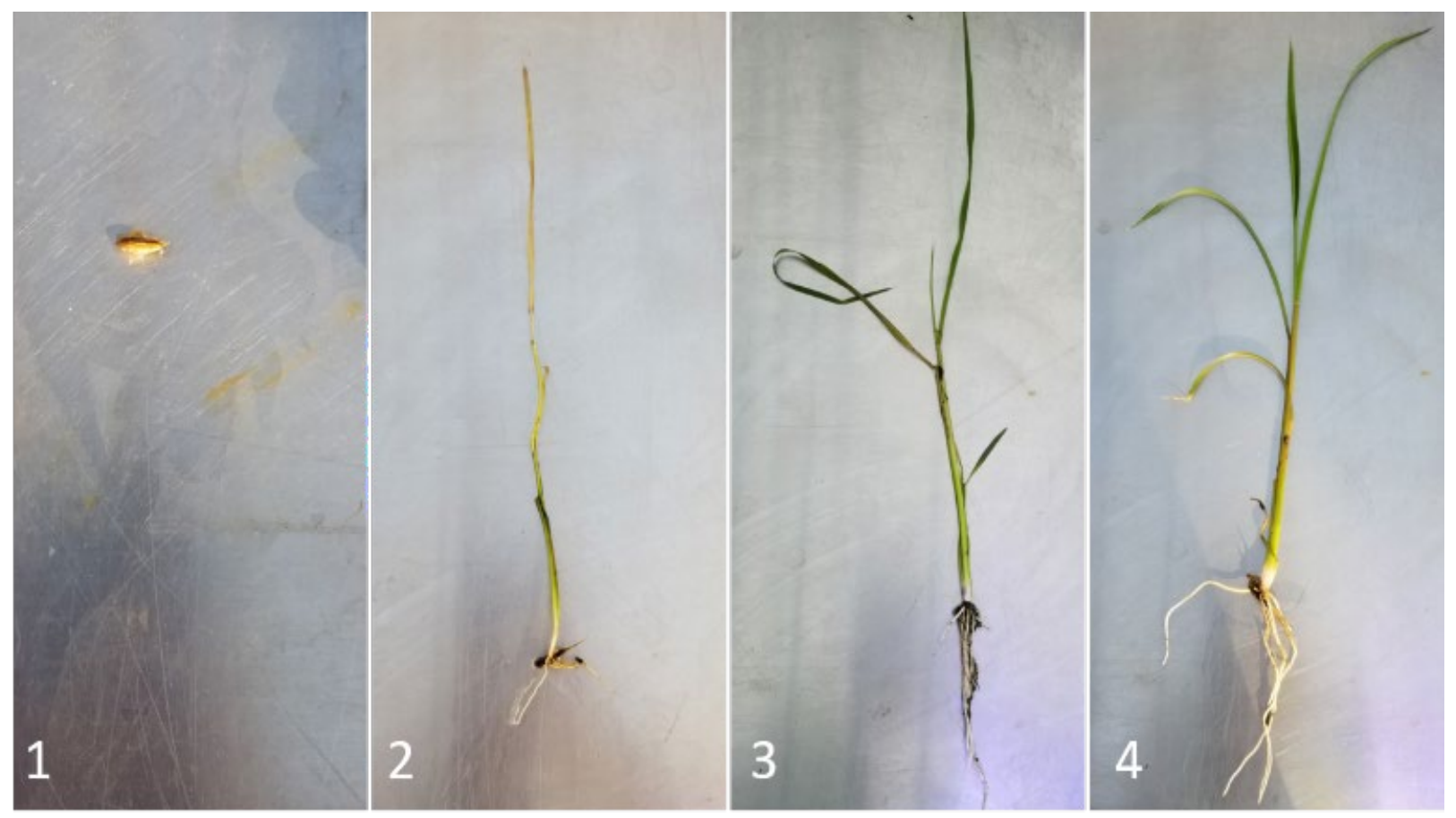

611 Figure 1. Plant health rating scale at 1 month of growth in the greenhouse of northern wild rice (NWR; Zizania palustris L.) following treatment with primary and secondary dormancy breaking treatments. 1: a dead plant, 2: a plant with significantly stunted growth and thin leaves, 3: a plant with relatively normal 615 


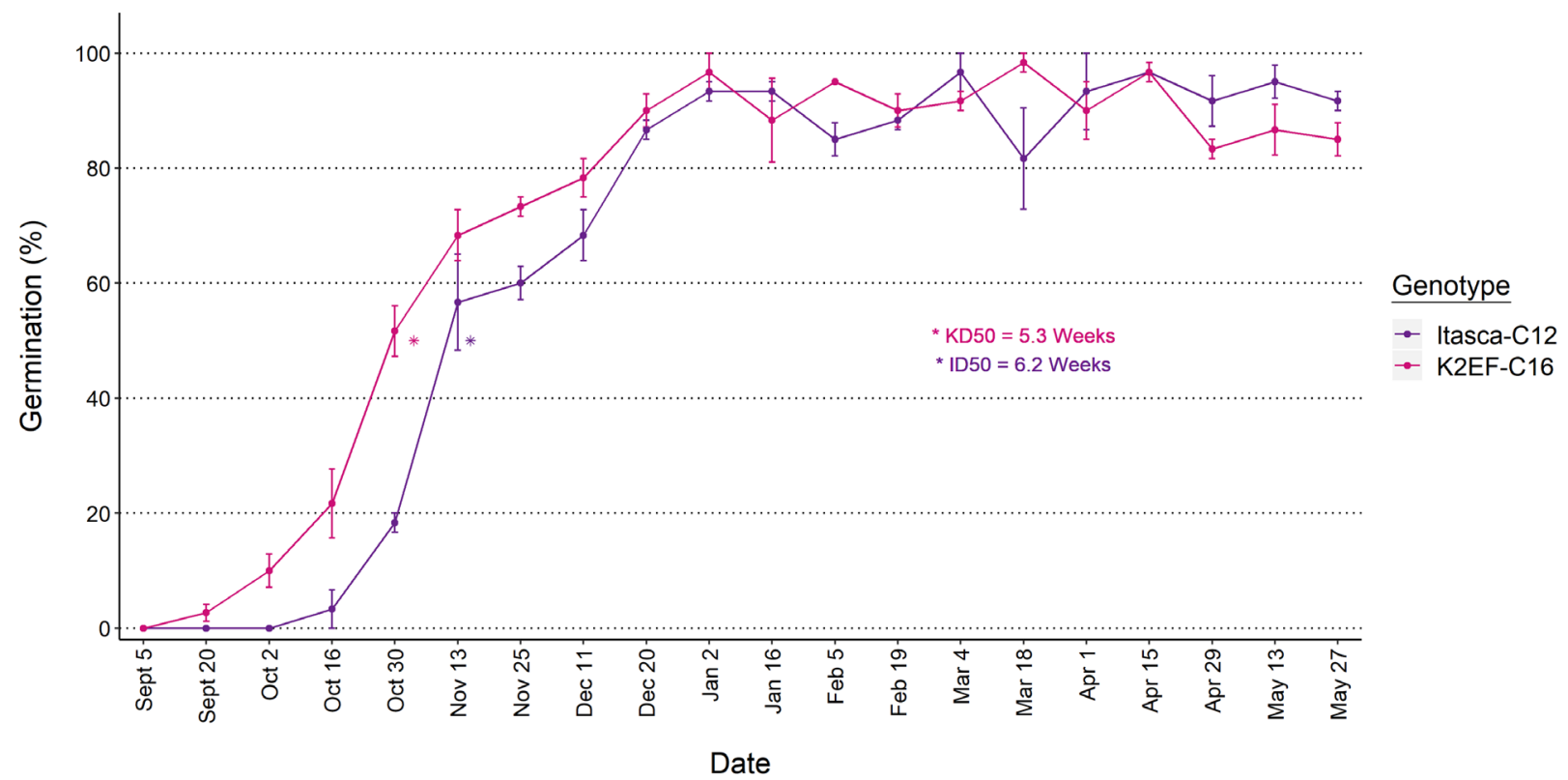

618 Figure 2. The germination of two genotypes, Itasca-C12 and K2EF-C16, of northern wild rice (NWR; 619 Zizania palustris L.) beginning after harvest, on September $5^{\text {th }}, 2019$ and ending 9 months later, on May $62027^{\text {th }}, 2020 . D_{50}$ values were a calculation of the time required for $50 \%$ of all viable seed to germinate for 621 each genotype.

622 

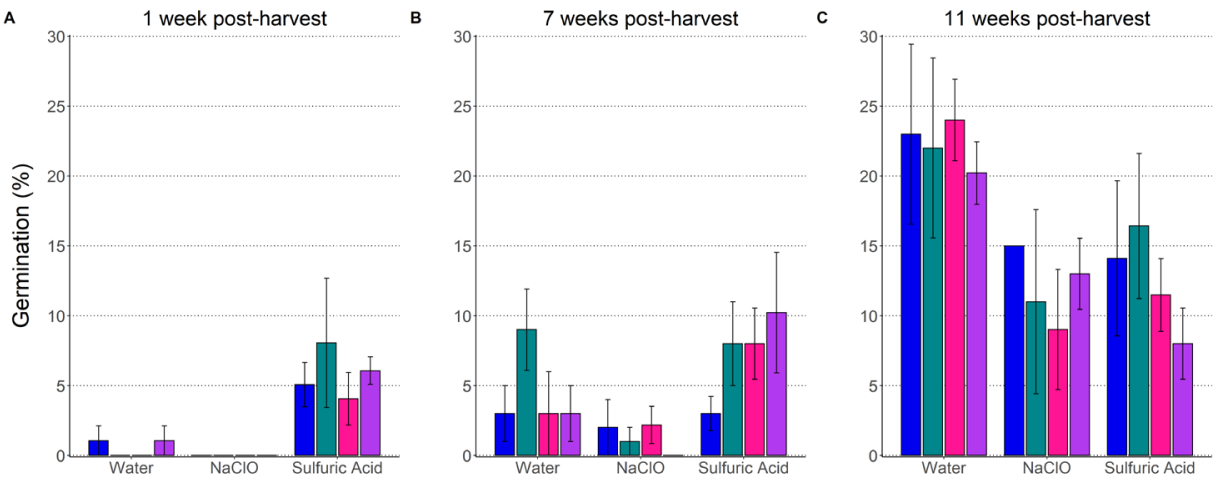

Secondary Treatment
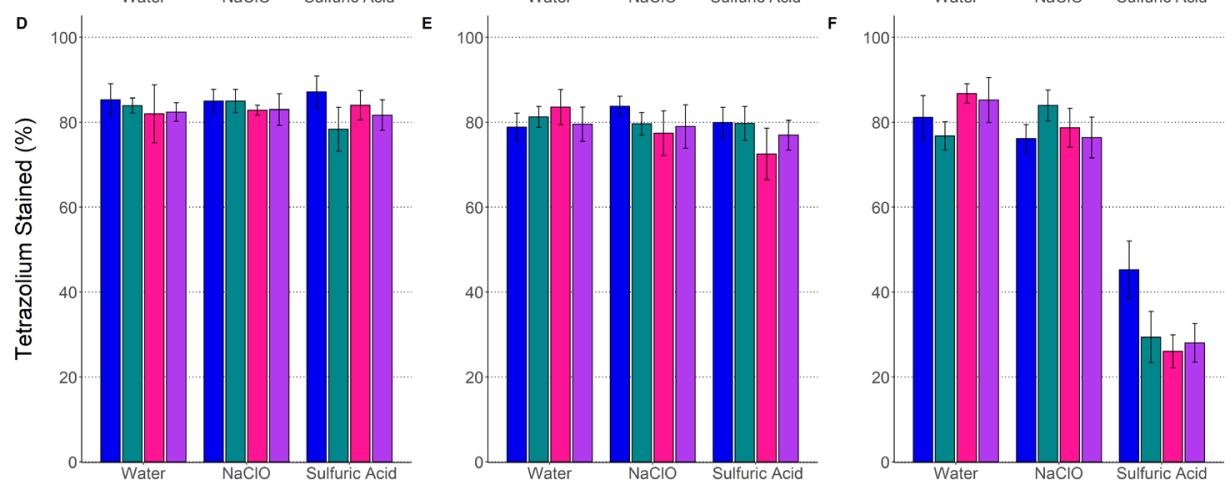

Water

Gibberellic acid

Giberellic acid \& Kinetin

Figure 3. The percent of germination (A-C) and tetrazolium staining (D-F) of northern wild rice (NWR; Zizania palustris L.) at 1 (A and D), 7 (B and E), and 11 (C and F) weeks post-harvest, following primary 628 

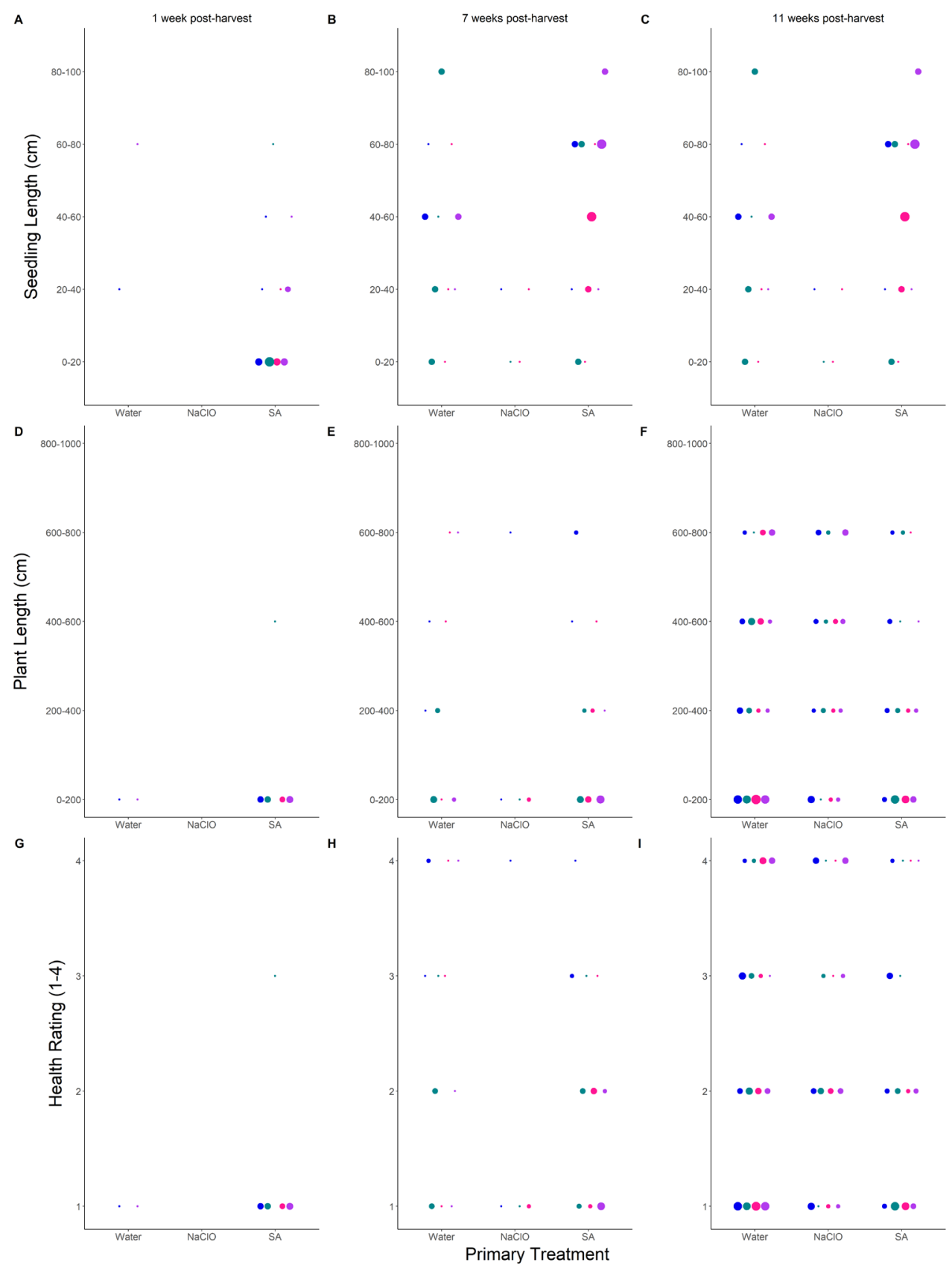

631 Figure 4. The seedling length (A-C), plant length (D-F), and plant health ratings (G-I) of northern wild rice 632 (NWR; Zizania palustris L.) at 1 (A, D, and G), 7 (B, E and H), and 11 (C, F, and I) weeks post-harvest 633 following primary and secondary dormancy treatments. 
Supplementary Table 1. The number of individuals tested, mean seedling length, and mean plant length of northern wild rice (NWR; Zizania palustris L.) at 1, 7, or 11 weeks post-harvest and following primary and secondary dormancy treatments.

\begin{tabular}{|c|c|c|c|c|c|}
\hline Trial & \begin{tabular}{|l|} 
Primary \\
Treatment
\end{tabular} & $\begin{array}{l}\text { Secondary } \\
\text { Treatment }\end{array}$ & $\begin{array}{l}\text { Number of } \\
\text { individuals }\end{array}$ & $\begin{array}{l}\text { Mean seedling } \\
\text { length }(\mathrm{cm}) \\
\end{array}$ & $\begin{array}{l}\text { Mean plant } \\
\text { length }(\mathrm{cm})\end{array}$ \\
\hline \multirow{6}{*}{$\begin{array}{l}1 \text { week post- } \\
\text { harvest }\end{array}$} & Water & Water & 1 & \begin{tabular}{|r|}
21.24 \\
\end{tabular} & $\begin{array}{r}0.00 \\
\end{array}$ \\
\hline & Water & GA and Kinetin & 1 & 73.76 & 0.00 \\
\hline & Sulfuric Acid & Water & 5 & 20.42 & 0.00 \\
\hline & Sulfuric Acid & GA & 6 & 22.17 & 75.19 \\
\hline & Sulfuric Acid & Kinetin & 4 & 16.91 & 0.00 \\
\hline & Sulfuric Acid & GA and Kinetin & 6 & 26.08 & 0.00 \\
\hline \multirow{11}{*}{$\begin{array}{l}7 \text { weeks post- } \\
\text { harvest }\end{array}$} & Water & Water & 3 & 57.69 & 563.23 \\
\hline & Water & GA & 9 & 65.65 & 132.42 \\
\hline & Water & Kinetin & 3 & 38.63 & 372.33 \\
\hline & Water & GA and Kinetin & 3 & 50.42 & 286.43 \\
\hline & $\mathrm{NaClO}$ & Water & 2 & 71.63 & 354.65 \\
\hline & $\mathrm{NaClO}$ & GA & 1 & 18.72 & 0.00 \\
\hline & $\mathrm{NaClO}$ & Kinetin & 2 & 29.33 & 0.00 \\
\hline & Sulfuric Acid & Water & 3 & 58.76 & 631.80 \\
\hline & Sulfuric Acid & GA & 8 & 94.61 & 119.51 \\
\hline & Sulfuric Acid & Kinetin & 8 & 41.16 & 180.60 \\
\hline & Sulfuric Acid & GA and Kinetin & 10 & 58.83 & 32.41 \\
\hline \multirow{12}{*}{$\begin{array}{l}11 \text { weeks post- } \\
\text { harvest }\end{array}$} & Water & Water & 23 & 37.74 & 283.61 \\
\hline & Water & GA & 22 & 45.06 & 260.00 \\
\hline & Water & Kinetin & 24 & 35.08 & 248.86 \\
\hline & Water & GA and Kinetin & 20 & 47.04 & 298.77 \\
\hline & $\mathrm{NaClO}$ & Water & 16 & 29.63 & 313.25 \\
\hline & $\mathrm{NaClO}$ & GA & 11 & 67.75 & 489.32 \\
\hline & $\mathrm{NaClO}$ & Kinetin & 9 & 32.26 & 372.08 \\
\hline & $\mathrm{NaClO}$ & GA and Kinetin & 13 & 47.85 & 496.04 \\
\hline & Sulfuric Acid & Water & 14 & 53.67 & 430.55 \\
\hline & Sulfuric Acid & GA & 17 & 93.96 & 164.00 \\
\hline & Sulfuric Acid & Kinetin & 11 & 34.48 & 129.61 \\
\hline & Sulfuric Acid & GA and Kinetin & 8 & 69.07 & 211.74 \\
\hline
\end{tabular}

